\title{
HISTÓRIAS DE VIDA POR AUTOBIOGRAFIAS: INSPIRAÇÕES NA CONSTITUIÇÃO DOCENTE
}

\author{
LIFE STORIES THROUGH AUTOBIOGRAPHIES: INSPIRATIONS IN THE TEACHING CONSTITUTION \\ HISTORIAS DE VIDA A TRAVÉS DE AUTOBIOGRAFÍA: INSPIRACIONES EN EL DESARROLLO DEL \\ DOCENTE
}

\author{
Tatiane Peres Zawaski \\ Mestre em Educação pela Universidade La Salle. \\ Orcid: https://orcid.org/0000-0003-2272-9671. \\ E-mail: tatiane.zawaski@hotmail.com. \\ Gilberto Ferreira da Silva \\ Doutor em Educação pela Universidade La Salle . \\ Orcid: https://orcid.org/0000-0002-6294-2322. \\ E-mail: gilberto.silva@unilasalle.edu.br.
}

\begin{abstract}
RESUMO
Este estudo toma como foco a constituição docente, presente nas histórias de vida dos educadores, a partir de registros autobiográficos. O estudo origina-se de uma pesquisa realizada em nível de mestrado que teve por objetivo analisar como os professores do ensino médio, de uma escola da rede privada, da região metropolitana de Porto Alegre, se formam como profissionais da educação. Os pressupostos teóricos estão embasados nos conceitos de Josso (2010) e Abrahão (2003; 2004; 2011), principalmente. Na análise, atentase aos motivos da escolha profissional, os primeiros contatos com a docência e os processos de constituição docente. As análises dos registros destacam a importância do formar-se em serviço, as trocas entre pares no ambiente de trabalho, a disponibilidade para acolher o outro e as figuras de professores guardadas na memória. Esses últimos acabam assumindo um lugar de evidência que orienta e aponta para horizontes de expectativas, materializadas na escolha da profissão docente.
\end{abstract}

Palavras-chave: Autobiografia. Constituição docente. Histórias de vida. Formação de professores.

\begin{abstract}
The present study focuses on the constitution of teachers, present in the life stories of educators, based on autobiographical records. The study originates from a research carried out at the master's level that aimed to analyze how high school teachers, from a private school, form themselves as education professionals. The theoretical assumptions are based on the concepts of Josso (2010) and Abrahão (2003; 2004; 2011), mainly. In the analysis, attention is given to the reasons for the professional choice, the first contacts with teaching, and the processes of teacher constitution. The records' analyses highlight the importance of service training, exchanges between peers in the work environment, the availability to welcome the other, and teachers' figures in memory. The latter end up assuming a place of evidence that guides and points to horizons of expectations, materialized in the choice of the teaching profession.
\end{abstract}

Keywords: Autobiography. Teaching constitution. Life stories. Teacher training.

\section{RESUMEN}

El presente estudio se centra en la formación docente, presente en las historias de vida de los educadores, basadas en registros autobiográficos. El estudio se origina en una investigación realizada a nivel de maestría que tenía como objetivo analizar cómo los profesores de secundaria, de una escuela privada, de la región de 
Porto Alegre, se han desarrollado como profesionales de la educación. Los supuestos teóricos se basan en los conceptos de Josso (2010) y Abrahão (2003; 2004; 2011), principalmente. En el análisis, se pone atención en las razones de la elección profesional, los primeros contactos con la enseñanza y los procesos de formación docente. Los análisis de los registros resaltan la importancia de la capacitación en servicio, los intercambios entre pares en el ambiente de trabajo, la disponibilidad para acoger al otro y las figuras de los maestros guardadas en la memoria. Estos últimos terminan asumiendo un sitial de evidencia, que orienta y apunta a horizontes de expectativas, materializadas en la elección de la profesión docente.

Palabras-clave: Autobiografía. Desarrollo del docente. Historias de vida. Formación de profesores.

\section{INTRODUÇÃO}

Esse texto é parte dos estudos realizados na pesquisa para a obtenção do título de mestre em educação (ZAWASKI, 2019). Tem como propósito analisar como os professores do ensino médio, de uma escola da rede privada da região metropolitana de Porto Alegre, se constituem como profissionais da educação. A pesquisa com histórias de vida oportuniza ao sujeito a reconstrução de sua memória, um revisitar de suas vivências, e com isso auxilia na compreensão e reconstrução do trajeto que permitiu forjar o profissional docente.

Nesse processo reconstrutivo, observam-se as marcas formativas, advindas das diversas relações que se estabelecem consigo e com os outros, em uma caminhada interlocutiva em que se produzem relações dialógicas entre eu/outro em busca do desenvolvimento profissional, já que somos uma imbricação de histórias em meio a tantas vozes que se visibilizam em nossa caminhada.

A seguir apresentam-se os caminhos teóricos percorridos, que permitiram discutir alguns conceitos considerados fundamentais para o entendimento e a reflexão sobre as categorias de análise que emergiram dos registros autobiográficos. Na sequência, apresentam-se os aportes metodológicos que orientaram a produção, tratamento e análise dos dados. As categorias de análise conjugam os esforços de interpretação. Finalmente, apresentam-se algumas considerações finais em formato de síntese. 


\section{Construindo os enfoques teóricos: breves reflexões}

Uma pluralidade de experiências circunda a memória, por meio de momentos vivenciados na vida cotidiana, de cunho pessoal ou profissional. Ao propor um trabalho por meio da análise de autobiografias, cabe refletir sobre alguns conceitos-chave que permeiam esse contexto de pesquisa e que, em suma, são fundamentais para o seu entendimento. Entre outros pesquisadores, como Nóvoa (2000), Pineau (1988), Ferrarotti (1988) e Dominicé (1988), as pesquisadoras Josso (2010) e Abrahão (2003; 2004; 2011) são fontes de referência para estudos de histórias de vida'.

As histórias de vida são consideradas por Josso (2010) como uma oportunidade que o sujeito pode experimentar: “[...] de tomada de consciência sobre seus diferentes registros de expressão e de representações de si, assim como sobre as dinâmicas que orientam a formação" (JOSSO, 2010, p. 69). Entende-se que as histórias de vida proporcionam ao sujeito uma reflexão a partir das experiências por ele vivenciadas. A partir desse ato, são possibilitadas tomadas de decisões futuras no que tange ao processo de ação e formação.

Ainda, no entendimento de Josso (2010), a abordagem autobiográfica permite um processo de investigação/formação. É considerada investigação porque está vinculada à produção de conhecimentos experienciais e é formação por proporcionar uma tomada de consciência de si e de suas aprendizagens, por parte do indivíduo.

Abrahão (2011) condiciona a reflexão a partir do conceito de (re)significação do vivido. As narrativas, presentes na autobiografia, proporcionam aprendizagem e autoconhecimento do trabalho docente, já que por meio do diálogo há uma valorização da voz do educador, de forma que, ao ouvir sua história, compreendem-se os fatores que incidem em sua prática. Sendo assim, a autora demarca a autobiografia como promotora da reconstrução do sentido do trabalho pedagógico, pois por meio da reconstrutividade da memória, há uma reflexão sobre o exercício da profissão (ABRAHÃO, 2003). Considerase, também, a vida como um espaço de formação, já que a história de vida perpassa pelo

\footnotetext{
${ }^{1}$ Entende-se, assim como Souza (2006), que as histórias de vida comportam uma variedade de fontes e procedimentos de recolha de dados. Entre os instrumentos utilizarei, nessa pesquisa, as autobiografias.
} 
contexto familiar, por meio de experiências que se estendem entre a vida social e profissional.

Nas pesquisas de Josso (2010), o termo “experiência formadora" tem um significado fundamental, pois "O conceito de experiência formadora implica uma articulação conscientemente elaborada entre atividade, sensibilidade, afetividade e ideação. A articulação que se objetiva numa representação e numa competência". E, segue a autora: "a formação é experiencial ou então não é formação, mas a sua incidência nas transformações de nossa subjetividade e das nossas identidades pode ser mais ou menos significativa" (JOSSO, 2010, p. 48).

\section{Trajeto metodológico}

A referida pesquisa trata-se de um estudo de cunho qualitativo, cujo objetivo é analisar como os professores do ensino médio, de uma escola da rede privada da região metropolitana de Porto Alegre, se constituem como profissionais da educação. Para a produção dos dados explorou-se a autobiografia. Esta possui um imensurável valor heurístico e, ainda assim, entendemos que é um instrumento de resgate de trajetórias e projetos com uma significativa função, pois reflete sobre o passado, presente e futuro (BRANDÃO, 2008).

Participaram da pesquisa três professoras que atuam no ensino médio, de uma escola da rede privada de educação, da região metropolitana de Porto Alegre. A seleção dos educadores considerou: a) Tempo de atuação no ensino médio igual ou superior a oito anos; b) Curso de Especialização Lato Sensu na área de atuação; c) Área do conhecimento distinta, a fim de que se tenha diversidade de percepções do processo formativo.

A fim de orientar e contribuir para a construção da autobiografia foi disponibilizado um roteiro que procurou facilitar a elaboração da escrita, partindo do pressuposto de que este não é um exercício comum aos profissionais da educação básica. O roteiro elencou um conjunto de temas que partiam das primeiras experiências na relação com a profissão até a sua formalização, passando pela escolarização e ensino superior. Durante um período que envolveu aproximadamente 60 dias, foi possível obter os registros dos três educadores, participantes da pesquisa. 
Para o tratamento das informações obtidas nos registros autobiográficos, utilizamos a Análise Textual Discursiva - ATD (MORAES; GALIAZZI, 2016). O uso dessa abordagem valoriza o potencial interpretativo e contribui para a construção de uma reflexão amparada em um processo que reconstrói as informações e desse movimento emergem as interpretações.

O processo de análise iniciou com a realização da unitarização ou desmontagem do texto, organizado em uma tabela do Microsoft Word, a fim de que se distinguissem unidades de análise, identificadas, de acordo com Moraes e Galiazzi (2016), como unidades de sentido ou também de significado. Desta dinâmica três categorias ganham visibilidade e acabam integrando o corpus de análise deste trabalho.

\section{Sobre as categorias de análise}

\section{a) A escolha pela carreira docente}

A escolha profissional está imbricada com a vida pessoal de cada ser. Quanto à docência, Holly (2000) avalia que não é apenas uma parte de nós que se torna professor, pois a docência compreende a nossa totalidade, ou seja, une-se aqui o pessoal com o profissional. A partir da escolha e do processo formativo há uma transformação que perpassa por todo o ser. Na concepção de Josso (2010), esse conjunto de vividos, advindos das experiências pessoais e profissionais, vão transformando o sujeito ao longo da vida, o que possibilita uma reflexão sobre suas heranças, valores, desejos e oportunidades.

Diante dos dados coletados por meio da produção autobiográfica, constata-se no relato da professora "A", sua escolha em virtude da afinidade com a disciplina de atuação, já que destacou ter facilidade com a mesma. Segundo a educadora:

Nesta escola o professor L. S. foi meu professor das disciplinas de Matemática e Física durante os três anos do $2^{\circ}$ grau. Identifiquei-me muito com ele e passei a admirar ainda mais as exatas. Na época, o ano letivo era dividido em bimestres e sempre no terceiro bimestre eu já tinha atingido nas duas disciplinas os 270 pontos necessários para aprovação. Mesmo assim, no último bimestre me dedicava igualmente fechando o ano com excelentes notas. Era bem comum eu gabaritar as provas de exatas, pois além da facilidade que eu tinha, o professor era fantástico e me fazia gostar cada vez mais da matéria (Autobiografia da Professora A). 
Considerando o destaque mencionado acima, percebe-se, de forma veemente, o processo de ressignificação do vivido, tendo em vista que a escolha profissional se deu a partir da admiração por um professor. Nesse sentido, compreende-se a profissão docente como um espaço de vida que se perpetua através do “outro" (ABRAHÃO, 2011).

A professora “B” relata em sua autobiografa certa indecisão quanto à escolha profissional; chegou a iniciar outra licenciatura, a qual se distancia muito da escolhida posteriormente. De acordo com o seu relato, a busca pela reopção de curso se efetivou a partir de sua análise, assim como por meio de conversa com familiares e a realização de testes vocacionais. Sobre a nova escolha, declara: “[...] tenho certeza de que cursar Letras foi uma das escolhas mais importantes que eu fiz, pois nesse universo da licenciatura em língua portuguesa eu me encontrei como profissional e como pessoa" (Autobiografia da Professora B).

As lembranças que foram registradas nesse momento remetem para uma satisfação na realização do curso "Durante o curso, houve muitos momentos de satisfação por estar conhecendo todas as teorias e por ter a oportunidade de discutir aspectos relacionados à língua”. E em formato de síntese conclui: “Quando do momento da feitura do trabalho de conclusão, eu pude me aprofundar em uma questão que me encanta: os quadrinhos" (Autobiografia da Professora B).

O encontro entre o "eu profissional" e o "eu pessoal” são marcas na autobiografia da docente. Aqui se inicia a compreensão do processo de busca da identidade, o que coincide com Eckert-Hoff (2008, p. 26), quando enfatiza que: “(re)significar a formação significa apropriar-se do 'estranho', do outro, vozes que se somando a outras, vêm construir, de forma heterogênea e cindida, o processo de identificação do sujeito".

Já em uma perspectiva diferente da educadora anterior, a professora "C" experimenta o momento de escolha profissional como uma fase difícil frente às indecisões: “Prestei o vestibular para Ciências da Computação e para Licenciatura em Física. (...). Na verdade, eu pensava em fazer Engenharia, mas não sabia se queria Elétrica, ou Civil, ou de Automação... Era nítida minha indecisão profissional” (Autobiografia da Professora C). As frustrações nesta trajetória são mais evidentes nesta descrição: “As disciplinas eram difíceis e eu, pensava, que era uma excelente aluna fui apresentada a uma realidade cruel e as frustações se tornaram rotina. Minhas notas excelentes durante todo Ensino Básico, 
sem muito esforço, se mostraram inúteis para as disciplinas do curso de Física" (Autobiografia da Professora C).

Sobre essas frustrações compreende-se a importância da experiência; há diferenças pontuais no campo do conhecimento; entre essas, a exigência que se apresenta a um aluno em nível médio se distancia da que tem que enfrentar um estudante da graduação. Nesta direção Josso bem esclarece: "não é somente compreender como nos formamos e nos transformamos, ao longo de nossa vida, mediante um conjunto de vividos transformados em experiências (...)" (2010, p. 65), mas é também nos situar em contexto concreto onde essas experiências se dão, acontecem e como elas acontecem, para então ressignificá-las. Segue Josso enfatizando o quanto é importante realizar essas articulações de "nossas heranças, nossas experiências formadoras, nossas pertenças, nossas valorizações, nossos desejos e o nosso imaginário às oportunidades socioculturais que saberemos aprender, criar e explorar [...]" (JOSSO, 2010, p. 65).

Assim, em busca da formação e da autoformação concebem-se as experiências como aportes fundamentais para que as escolhas sejam efetivadas, ou remanejadas, como no caso da professora "B". A fim de que o percurso de vida fosse modificado, coube um processo de ação-reflexão, explicitado no conhecimento de si para a tomada de decisão.

Fundando-se em um processo de experiências em que se tende a considerar as expectativas futuras, a noção aportada por Koselleck (2006), denominada de horizonte de expectativas, contribui para a compreensão do que ocorre nas escolhas que se fazem ao longo da vida, em especial aquelas que acabam por orientar a atuação profissional:

Horizonte quer dizer aquela linha por trás da qual se abre no futuro um novo espaço de experiência, mas um espaço que ainda não pode ser contemplado. A possibilidade de se descobrir o futuro, apesar de os prognósticos serem possíveis, se depara com um limite absoluto, pois ela não pode ser experimentada (KOSELLECK, 2006, p. 311).

À vista de uma possibilidade de decidir os caminhos a serem percorridos, mesmo que ainda não se tenham experiências efetivadas, as participantes da pesquisa se permitem pensar no futuro por meio de suas escolhas profissionais. A professora "A" escolhe a profissão a partir da admiração por um docente; vislumbra a sua atuação concomitante ao que ele fazia em suas práticas. O processo de indecisão perpetuado no caminho de " $B$ " e "C" as faz refletir sobre o futuro, de forma que " $B$ " decide trocar o seu percurso, com a reopção do curso, enquanto “ C", mesmo indecisa, segue na profissão para 
a qual fora aprovada, tendo que lidar com as frustrações advindas da necessidade de um esforço que até então não tinha sido experienciado; afirmou-se só depois de ingressar como Bolsista de Iniciação Científica, auxiliando educandos que, como ela, vinham com bases debilitadas e com falta de conhecimento.

\section{b) A inserção na docência}

No início da carreira os docentes se deparam com um processo tenso e, não raras vezes, permeado pela insegurança. Carlos Marcelo Garcia (2010, p. 29), refletindo sobre este momento profissional, enfatiza tudo o que o docente em um curto espaço de tempo precisa: "adquirir conhecimentos sobre os alunos, o currículo e o contexto escolar; delinear adequadamente o currículo e o ensino; começar a desenvolver um repertório docente que Ihes permita sobreviver como professor [...]”. Não raras vezes também precisa dar conta de aspectos que não estão ligados diretamente à docência, mas que fazem parte da vida cotidiana de uma comunidade escolar, como é o caso da busca pelo aperfeiçoamento profissional e as questões ligadas à gestão propriamente dita do ambiente escolar.

Ao ingressar em um espaço educativo, o docente alia a teoria com a prática e busca relações plurais que atravessem a sua. Sabe-se que o primeiro contato é regido por expectativas, mas, acima de tudo, compactua-se com Silva (2008), que remete ao início da carreira como um momento em que lembranças da maneira de ser e agir de alguns docentes do passado são reconstruídas e ressignificadas no presente.

A categoria "inserção docente" objetivou analisar como decorreu o contato e a inserção na docência. Buscou-se localizar os anseios, as expectativas e as experiências que demarcaram essa fase e como foram sendo construídas estratégias para experimentar modos de ser na profissão.

Observa-se que experiências do exercício da docência, durante o curso de licenciatura, acabam por transformar-se em situações que marcam, alicerçam e confirmam a opção escolhida, garantindo um encantamento pela profissão. Assim se refere uma das educadoras em seus registros autobiográficos: "Durante a faculdade dei aulas voluntárias no EJA, dentro da própria faculdade e comecei ali a me apaixonar por ensinar. Ajudava muito os colegas que tinham dificuldades e via a grande facilidade que tinha em transmitir meu conhecimento" (Professora A). 
O voluntariado é uma prática bastante comum em cursos que formam profissionais do campo da educação e, não raras vezes, os acadêmicos acabam se envolvendo em projetos educativos durante seu processo formativo para além dos estágios regulares que compõem a estrutura curricular. Coracini, nesta direção, assim aponta:

[...] a formação do professor começa muito antes da escolha profissional, nas primeiras experiências na escola, nos primeiros cursos, e é por isso que, não raro, são as experiências e representações anteriores à prática de ensino, anteriores mesmo ao curso de graduação que determinam o desempenho do professor: ora é um mestre que de alguma maneira, tenha marcado a infância ou a adolescência, ora são as primeiras experiências com aulas que se revelam principais responsáveis pela construção da imagem que, embora em constante movimento, permanecem no inconsciente (CORACINI, 2000, p. 6).

A professora "B" traz relatos mais sucintos do início de sua carreira docente. Descreve que tão logo concluiu a graduação, participou de uma seleção na rede em que atua até hoje, como professora de anos iniciais e, no ano seguinte, fora convidada para ministrar as aulas de Língua Portuguesa para o Ensino Fundamental II. Em 2011, a educadora solicitou transferência desta instituição, visto que recebeu o convite para atuar em outra da mesma rede, mais próxima de sua residência. Como relatado abaixo:

\footnotetext{
Devido a isso, pedi transferência para essa unidade em razão de tudo o que ela representava em termos de oportunidades de crescimento profissional, já que eu poderia me dedicar a uma proposta de ensino focada no fundamental. Além disso, motivou-me também a questão logística, já que eu estaria trabalhando no município onde resido. Isso reverbera em gestão de tempo e qualidade de vida (Autobiografia da Professora B).
}

A busca pela qualidade de vida, aliada ao desejo de ensinar, são pontos que merecem destaque no relato da professora "B". Corroborando com Vaillant (2016), um bom ensino requer o reconhecimento do educador, de forma que ele se sinta pertencente ao espaço no qual está inserido e nele se desenvolva enquanto profissional da educação. Além das atividades como docente, esta mesma rede oportunizou à educadora " $B$ " outras possibilidades de atuação; como ela relembra, a tutoria presencial, no curso de Pedagogia, e a correção das redações nas provas do vestibular. Todas essas atividades são apontadas por ela como fundamentais para sua formação e para o seu aprimoramento profissional, como declara:

Estou em sala de aula há treze anos, a caminhada é importante para nos dar a experiência e o jogo de cintura de que necessitamos. Tenho a ideia fixa de que o professor necessita estar em permanente atualização. Outro fator que julgo importante é ouvir os alunos. Muitas vezes são eles, com seus comentários, que me fazem viajar na criação de muitos projetos (Autobiografia da Professora B). 
Constata-se que o percurso profissional da educadora na instituição a faz buscar, constantemente, conhecimento e aperfeiçoamento. As oportunidades a constituem enquanto profissional da área educacional, como ela mesma aponta. Nesse sentido, esse mundo experiencial que vive vai transformando o seu fazer, possibilitando novas experiências. A professora " $C$ " teve seu contato com a docência ainda na graduação. No quarto semestre assumiu quarenta horas como docente contratada da rede estadual de ensino, nas disciplinas de Ciências, Física e Matemática. Segundo ela:

Eu tinha vinte e um anos e precisa enfrentar adolescentes e adultos com muita segurança. Certamente estava com medo, alguns de meus colegas de faculdade tiveram experiências horríveis, odiaram a sala de aula. Eu adorei. A primeira lembrança que tenho é de entrar em uma turma de oitava série e nossos olhares eram esperando que algum lado começasse a interação. Eu comecei a falar e deu certo! (Autobiografia da Professora C).

Constata-se a insegurança e o medo, já que os relatos que tinha não eram dos mais positivos. Ao contrário do que ouviu, o encanto pela docência teve seu início nessa época. Recorrendo a Vaillant (2011), compreende-se que os sentimentos destacados pela educadora acima são comuns no início da carreira, contudo, se o professor possuir um domínio psicológico, assim como autoestima e autonomia, aliado à competência técnica, o exercício profissional transcorre com segurança e encantamento, como ocorrido com a educadora. "C" demarca um fator bem pertinente quando diferencia o ensino público do privado, no que tange às diferenças com o público. Segundo ela:

Trabalhei durante oito anos na Rede Estadual. Depois iniciei à docência na rede privada onde leciono até o momento. Mesmo que os alunos fossem de diferentes classes sociais percebia os mesmos problemas dos alunos dos adolescentes no Ensino Médio, presença e postura familiar. Os relatos são da falta que sentem da presença dos pais já que eles trabalham demais e não têm tempo, já cresceram e não precisam mais de cuidados, do divórcio que deixa o filho entre as brigas, sem auxílio (Autobiografia da Professora C).

Vaillant (2013) destaca que a profissão docente é uma daquelas profissões em que ficar sem atualização é quase impensável. Em uma sociedade mutável, onde muitos jovens estão com expostos a diferentes experiências que vão conformando identidades, é imperativo que o educador se mantenha atualizado e em sintonia com o que o cerca e com o que cerca seus alunos. Koselleck (2006), ao invocar a ideia "horizonte de expectativas", talvez possa nos ajudar a pensar que os processos formativos, que subjazem desde o início da formação na universidade, estendendo-se por toda a vida, ganham novos aportes quando pensados desde a perspectiva de uma inserção docente que valoriza as trocas, a 
realidade do educador e reconhece o valor profissional. Destaca-se, desde o início da carreira docente, um horizonte de expectativas no modo de atuar e como poderá se dar a construção da carreira docente ao longo da trajetória profissional.

\section{c) Constituição de ser professora e as inspirações na carreira}

A terceira categoria de análise compreende a "Constituição docente no Ensino Médio e as inspirações na carreira". Nesse processo de formação, que de certa forma aliase às inspirações que se tem no percurso da carreira, a professora "A" traz em seus registros, mais uma vez, a figura de um determinado professor, a quem já fizemos referência na primeira categoria. Em sua descrição, assim se refere: "Nesta escola o professor L. S. foi meu professor das disciplinas de Matemática e Física durante os três anos do $2^{\circ}$ grau. Identifiquei-me muito com ele e passei a admirar ainda mais as exatas" (Autobiografia Professora A). A relação entre o aprendizado do conteúdo e a empatia com o professor são elementos que garantem o sucesso na relação cognitiva. Diz a educadora: “Era bem comum eu gabaritar as provas de exatas, pois além da facilidade que eu tinha, o professor era fantástico e me fazia gostar cada vez mais da matéria. Formei-me no $2^{\circ}$ grau no ano de 1989" (Professora A).

O resultado desse sucesso conduz ao exercício da profissão no mesmo campo de conhecimento que o professor inspirador atua. Situação muito comum nas escolhas profissionais quando a identificação é marcada por experiências positivas. Comprova-se, a partir desse argumento, o que é apontado por Arroyo (2013), quando indica o quanto está presente em nossa constituição profissional a influência de diferentes experiências com educadores com os quais fomos entrando em contato ao longo de nossos processos formativos. O Professor "A" assim segue descrevendo: "Muitos professores marcaram minha vida na faculdade, dentre eles os professores C., P., N. e R. Tenho contato com eles até hoje pelas redes sociais e, também, pessoalmente, pois eles foram fundamentais para minha constituição como graduanda e, principalmente, como professora" (Autobiografia da Professora A).

Essas experiências, aos poucos, são incorporadas ao fazer docente e, por vezes, vão atribuindo sentido à prática profissional. Nessa direção, o lugar ocupado pelos pares na profissão assume, igualmente, importância. A educadora " $A$ " assim se refere: "Alguns 
colegas também me inspiram muito, pois me ensinam no dia a dia o amor pela profissão, a organização, o companheirismo, a parceria. Aprendo todos os dias com os mais velhos e os mais jovens e acredito que tenho que estar em constante evolução". Por outro lado, observa-se que a educadora, talvez pelo fato de perceber o quanto as interações com os colegas acabam por enriquecer o trabalho docente cotidiano, também se posiciona, ao dizer que: "Procuro sempre estar disponível a ajudar em toda e qualquer situação".

Josso (2010) chama de "caminhar para si" esse movimento que se coloca em abertura para o outro e para si mesmo, permitindo refletir sobre o que se faz e o que se vive. No excerto acima, vislumbra-se o reconhecimento que "A" destaca na aprendizagem junto aos pares; entende-se que sua formação se dá a partir das trocas com o outro, para a compreensão de como ocorre o processo formativo.

A professora "B" em seus registros destaca o quanto a atualização se faz importante para o seu crescimento. Remete aos relatos de alunos para buscar o encantamento frente aos projetos que realiza: "Outro fator que julgo importante é ouvir os alunos. Muitas vezes são eles, com seus comentários, que me fazem viajar na criação de muitos projetos”. É o educador lançando mão da experiência que forma, nutrir a ação docente do cotidiano: "Estou em sala de aula há treze anos, a caminhada é importante para nos dar a experiência e o jogo de cintura de que necessitamos. Tenho a ideia fixa de que o professor necessita estar em permanente atualização".

Raras são as descrições em que as inspirações para o constituir-se professor não se fazem presente. Para Josso (2010), a reflexão sobre si mesmo se perpetua através da autoorientação dos processos de ensino-aprendizagem. No excerto acima, constata-se que a educadora "B" busca, na qualificação, o seu desenvolvimento enquanto educadora, ao mesmo tempo em que se propõe escutar os alunos, para o planejamento de suas aulas. Atribui ao diálogo uma possibilidade de interação, compreendendo as especificidades que circundam a sua prática.

Na escuta, a professora "B" constitui-se docente a partir de novas experiências; coloca-se em um espaço que se abre a outras possibilidades, onde o diálogo a sensibiliza a buscar outras formas de fazer educação. É neste sentido que a capacidade de criar ou imaginar, como bem refere a educadora, inclina-se ao campo da experiência, abrindo-se também para a sensibilidade e a disponibilidade. 
Ao fazer-se professor, o profissional da educação reflete, em grande medida, o que a literatura vem insistindo nestes últimos anos. A profissão exige um continuum na formação iniciada na universidade e que estende por toda a vida. A educadora " C" relata algumas situações que acabaram sendo potencializadoras de um dar-se conta, de um pensar sobre, mesmo no caso de experiências que não foram positivas, como se pode observar na sequência: "Aprendi muito ao longo da minha jornada com os professores que tive, como fazer uma aula e como jamais proceder. Durante o Mestrado (...) havia professores extremamente cruéis e, inacreditavelmente, nós, alunos, nem achávamos isto estranho, porque nossos professores da faculdade já eram assim".

Essa capacidade de tomar as experiências para então, a partir delas, reconstruir aprendizados que acabam por orientar a ação profissional, vai configurando os elementos que forjam essa identidade profissional. Segue a educadora descrevendo a situação do tempo em que cursou o mestrado: "Uma professora simplesmente rasgou uma folha do meu caderno e esta mesma pessoa concedia a mesma nota para os alunos que apresentavam na data, cumpriam os requisitos e os que faziam atrasados e de qualquer jeito" (Autobiografia da Professora C). Do mesmo modo, outras situações mais animadoras e positivas acabam ganhando terreno nas lembranças e conquistando espaço na descrição autobiográfica: "Na faculdade lembro com muito carinho da exigência de alguns professores. Porque eles eram professores que faziam aulas maravilhosas, eram geniais, muitas vezes não entendia nada, mas eles encantavam" (Autobiografia da Professora C). O rigor do trabalho docente interpretado pela educadora, revela a compreensão de um comprometimento do professor universitário com a aquisição e produção de conhecimentos por parte dos estudantes e isso a educadora traduz na forma com que interpreta suas memórias: "Contudo, o que mais me encantava era a forma carinhosa escondida que eles exigiam, ficava claro que era para o nosso bem, para a nossa aprendizagem, até quando xingavam" (Autobiografia da Professora C). Finalmente, indica que alia a experiência de ser estudante com a constituição do ser docente, pois ambas contribuíram para a sua formação: “Acredito que me desenvolvi assim, buscando exigir e perceber o limite de cada um, incentivando e motivando, mostrando como eu amo o que eu faço e a minha alegria quando aprendemos" (Autobiografia da Professora C). 
A partir da análise da descrição acima, observa-se o quanto as palavras produzem sentido. A forma como algumas questões são colocadas, remete a situações as quais são relembradas como "cruéis", conforme descrito no relato de "C". A partir dessas lembranças, aliadas ao sentido que as palavras produzem, são criadas realidades as quais são demarcadas por Larrosa (2018) como mecanismos de subjetivação. Segundo o autor, esses mecanismos se instauram a partir do que experienciamos junto aos outros, por meio da escuta, da disponibilidade de aprender e da sensibilidade diante dessa exposição.

Ainda assim, marcas positivas foram deixadas pelos educadores que participaram de sua trajetória de formação; mesmo sem ter um total entendimento do conteúdo, as participantes sentiam encantamento na efetivação de sua prática. As marcas negativas servem, também, como forma de aprendizagem, que vem dotada de sentidos dos percursos que não se quer recorrer na caminhada docente, como bem expõe Arroyo: “Através da relação apaixonada de amor e ódio nos aprendemos e aprendemos formas diferentes, mais nossas de ser e vivenciar o magistério. Nem tudo o que somos nos pertence. Somos o que resultamos de tudo. Quanto fui, quanto não fui, tudo isso sou" (ARROYO, 2013, p. 36).

É nesse devir que os professores vão se constituindo enquanto sujeitos da educação. É pelas experiências que o ser se forma e se transforma. A docência é uma profissão em que o sujeito está sempre em transformação, seja por meio de sofrimento, com memórias fragilizadas de algumas situações, seja pela paixão, com rememorações de fatos marcantes, que nos fazem querer ser professores.

Observa-se, também, que a identidade profissional vai se construindo por meio dessas trocas, nos espaços que proporcionam diálogo, reflexão e aprendizagens. As trocas, advindas de comunidades de prática, propiciam a formação com um olhar que agrega sentido para a prática. Ampliar as experiências locais coloca-se como uma possibilidade, mas desloca o educador de mero consumidor de experiências para uma posição de produtor e, como tal, com autoridade para compartilhá-las.

\section{CONSIDERAÇÕES FINAIS}


Com o propósito de analisar como os professores do ensino médio, de uma escola da rede privada da região metropolitana, se constituem como profissionais da educação, esta investigação foi se delineando, na imersão dos registros autobiográficos produzidos pelos educadores participantes da pesquisa. Tal imersão permitiu construir o tratamento das informações obtidas e a análise, remetendo para alguns aspectos que passamos a sintetizar na sequência, a título de finalização.

O primeiro deles refere-se à insistência com que a literatura, tanto nacional quanto internacional, trata o campo da formação de professores nas últimas décadas. A formação é um continuum, que começa bem antes da própria formação inicial, no qual aliam-se experiências de vida, experiências escolares e experiências de formação.

O segundo aspecto opera no campo da subjetividade e refere-se às inspirações que foram assumindo lugar de significado para a opção pela carreira docente. Geralmente, no caso dos registros analisados, provindos de professores que marcaram a trajetória escolar dos educadores participantes da pesquisa. São figuras que, desde experiências positivas ou negativas, acabam por orientar tomadas de decisão na composição do lugar profissional assumido pelos educadores.

O terceiro aspecto refere-se ao processo permanente no ambiente de trabalho, ou seja, a formação em serviço, onde ocorrem, de forma fértil e produtiva, as trocas entre pares, a solidariedade profissional e o aperfeiçoamento das práticas docentes cotidianas. Dimensões havendo sido destacadas pelos educadores, resta a indagação para se pensar modos de propor, produzir e contemplar ações formativas que partam do lugar da ação educativa. Ali, o profissional da educação assume centralidade e protagonismo, talvez em detrimento do "menos o que vem de fora" para um "mais para o que representa a realidade daqueles que experimentam a educação".

\section{REFERÊNCIAS}

ABRAHÃO, Maria Helena Menna Barreto. Memória, narrativas e pesquisa autobiográfica. Revista História da Educação, ASPHE/FaE/UFPel, n. 14, set. 2003. p. 79-95. Disponível em: https://seer.ufrgs.br/asphe/article/view/30223. Acesso em: 06 jun. 2020.

ABRAHÃO, Maria Helena Menna Barreto. Identidade e vida de educadores rio-grandeses: narrativas em primeira pessoa (...e em muitas outras). Porto Alegre: EDIPUCRS, 2004. 
ABRAHÃO, Maria Helena Menna Barreto. Memoriais de formação: a (re)significação das imagens-lembranças/recordações-referenciais para a pedagoga em formação. Revista da Educação, Porto Alegre, v. 34, n. 2, maio/ago. 2011. p. 165-172. Disponível em: http://revistaseletronicas.pucrs.br/ojs/index.php/faced/article/viewFile/8708/6353 Acesso em: 06 jun. 2020.

ARROYO, Miguel G. Ofício de mestre: imagens e autoimagens. Petrópolis/RJ: Vozes, 2013.

BRANDÃO, Vera Maria Antonieta Tordino. Memória (auto)biográfica como prática de formação. Revista @mbienteeducação, São Paulo, v. 1, n. 1, jan./jul. 2008. Disponível em: http://publicacoes.unicid.edu.br/index.php/ambienteeducacao/article/view/572 Acesso em: 04 abr. 2020.

CORACINI, Maria José. Autonomia, poder e identidade na sala de aula. In: PASSEGI, Luis; OLIVEIRA, Maria dos S. Linguística e educação: gramática, discurso e ensino. São Paulo: Terceira Margem, 2000.

DOMINICÉ, Pierre. A biografia educativa: instrumento de investigação para a educação de adultos. In: NÓVOA, António; FINGER, Mathias. O método (auto)biográfico e a formação. Lisboa: MS/DRHS/CFAP, 1988.

ECKERT-HOFF, Beatriz M. Escritura de si e identidade: o sujeito-professor em formação. Campinas/SP: Mercado das Letras, 2008.

FERRAROTTI, Franco. Sobre a autonomia do método biográfico. In: NÓVOA, António; FINGER, Matthias (org.). 0 método (auto)biográfico e a formação. Lisboa: Ministério da Saúde. Depart. de Recursos Humanos da Saúde/Centro de Formação e Aperfeiçoamento Profissional, 1988. p. 17-34.

HOLLY, Mary Louise. Investigando a vida profissional dos professores: diários biográficos. In: NÓVOA, António. Vida de professores. Portugal: Porto Editora, 2000.

JOSSO, Marie-Christine. A experiência de vida e formação. São Paulo: Paulus, 2010.

KOSELLECK, Reinhart. Futuro passado: contribuição à semântica dos tempos históricos. Tradução: Wilma Patrícia Maas; Carlos Almeida Pereira. Rio de Janeiro: Contraponto/PUCRJ, 2006.

LARROSA, Jorge Bondía. Esperando não se sabe o quê: sobre o ofício de professor. Belo Horizonte: Autêntica, 2018.

MARCELO GARCIA, Carlos. O professor iniciante, a prática pedagógica e o sentido da experiência. Formação Docente, Belo Horizonte, v. 2, n. 3, ago./dez. 2010. p. 11-49. Disponível em: http://formacaodocente.autenticaeditora.com.br. Acesso em: 01 abr. 2020.

MORAES, Roque; GALIAZZI, Maria do Carmo. Análise textual discursiva. 3. ed.. ljuí: Unijuí, 2016. 
NÓVOA, António. Vida de professores. Portugal: Porto Editora, 2000.

PINEAU, Gaston. A autoformação no decurso da vida: entre hetero e a ecoformação. In: NÓVOA, António; FINGER, Matthias. 0 método (auto)biográfico e a formação. Lisboa: Ministério da Saúde, 1988. p. 65-77

SILVA, Maria Euzemar Berenice Rego. Caminhos da formação docente em práticas autobiográficas: relato de experiência. Revista da FARN, Natal, v. 7, n. 1, jan./jun. 2008. p 29-49.

Disponível em: http://revistas.unirn.edu.br/index.php/revistaunirn/article/download/134/163/. Acesso em: 01 abr. 2020.

SOUZA, Elizeu Clementino de. Pesquisa narrativa e escrita (auto) biográfica: interfaces metodológicas e formativas. In: SOUZA, Elizeu Clementino de; ABRAHÃO, M. H. M. B. Tempos, narrativas e ficções: a invenção de si. Porto Alegre: EDIPUCRS, 2006.

VAILLANT, Denise. Desarrollo profesional, evaluación y políticas docentes en Latinoamérica. Organización y Gestión Educativa, Espanha, n. 4, jul./ago. 2016. Disponível em: https://www.researchgate.net/publication/305986917_Desarrollo_profesional_evalua cion_y_politicas_docentes_en_Latinoamerica. Acesso em: 06 abr. 2020.

VAILLANT, Denise. Formación inicial del profesorado en América Latina: dilemas centrales y perspectivas. Revista Española de Educación Comparada, Madrid, v. 22, p. 185-206, 2013. Disponível em: http://revistas.uned.es/index.php/REEC/article/view/9329. Acesso em: 06 abr. 2020.

VAILLANT, Denise. La escuela latinoamericana en busca de líderes pedagógicos. EDUCAR, Barcelona, $\quad$ v. $47,2011 . \quad$ n. $2, \quad$ Disponível em: https://raco.cat/index.php/Educar/article/view/248539/o. Acesso em: 05 abr. 2020.

ZAWASKI, Tatiane Peres. A autobiografia no processo de constituição docente: reflexões sobre 'ser' professor do ensino médio. 2019. 136 f. Dissertação (Mestrado em Educação) Universidade La Salle, Canoas, 2019.

Recebido em: 06/02/2020

Parecer em: 20/08/2020

Aprovado em: 30/01/2021 